REDES- Revista hispana para el análisis de redes sociales.

Vol.3,\#2, sept-nov. 2002.

http://revista-redes. rediris.es

\title{
Redes sociales y partidos políticos en Chile
}

Larissa Adler Lomnitz

IIMAS-UNAM

\section{Resumen}

En este estudio se describe el origen y la evolución de dos partidos políticos chilenos (el Partido Radical y el Partido Demócrata Cristiano) por medio del análisis de las redes sociales que los originaron y que los componen. Se propone un modelo teórico que consiste en la combinación de un análisis estructural basado en el estudio de redes sociales y en la descripción del sistema simbólico que las retroalimenta. La estructura y función de las redes sociales depende de la dirección en la que se dan los intercambios -redes horizontales y redes verticales-, de lo que se intercambia, y de la articulación que se da entre las redes. En toda sociedad se dan intercambios simétricos y asimétricos, que van conformando redes horizontales y verticales. Estas redes se van articulando entre sí, conformando el tejido social. El predominio de unas sobre otras y su combinación dan el carácter a la cultura política (ejemplo, autoritaria vs. igualitaria). En el caso de Chile encontramos que se trata de una sociedad horizontalmente estructurada en clases sociales, al interior de las cuales se advierten redes sociales informales que eventualmente y por razones ideológicas se van formalizando en partidos políticos. Estos grupos igualitarios de amigos ejercen informalmente control sobre sus propios miembros creando barreras invisibles que los distinguen de los demás, y aunque si bien es cierto que en ellos surgen líderes "naturales", su liderazgo es condicional lo que permite el surgimiento de tendencias y facciones que a su vez pueden llegar a constituirse en nuevos partidos. Por ende, el sistema depende de negociaciones horizontales permanentes mediadas por un fuerte presidencialismo dentro de un sistema parlamentario fuerte y apoyado por una legitimidad casi fanática.

\section{El Modelo}

Entendemos la cultura política como un lenguaje de comportamiento compuesto por la "gramática" (la langue) y el "habla" (la parole). La gramática es el conjunto de categorías y reglas que representa la continuidad en la cultura, y el habla es su 
comportamiento lingüístico, el cual es por naturaleza variable. Los cambios que se van dando en una sociedad (tecnológicos, económicos, políticos), deben enfrentarse a su estructura, y el resultado de la adecuación entre las fuerzas conservadoras y las del cambio va constituyendo su historia; los cambios son interpretados y asimilados por la continuidad de la cultura. Los grandes y bruscos cambios en la gramática cultural se dan en momentos cataclísmicos (conquista, guerras, revoluciones). De otra manera, los cambios son lentos; los eventos van actuando sobre la cultura en forma gradual. La gente actúa, absorbe y asimila los cambios a partir de la gramática cultural preexistente. En ello consiste la dinámica de la continuidad y el cambio.

En este contexto, la cultura política vendría a ser la gramática de las relaciones de dominación/subordinación/cooperación; es decir, la gramática del control social: del poder y su forma de expresarse.

Proponemos definir la cultura política sobre la base de:

1) la estructura de las redes sociales que tienen relación con el poder y

2) la del sistema simbólico que legitima y retroalimenta ese poder

1) La estructura y función de las redes sociales depende de la dirección en la que se dan los intercambios -redes horizontales y redes verticales-, de lo que se intercambia, y de la articulación que se da entre las redes. En toda sociedad se dan intercambios simétricos y asimétricos, que van conformando redes horizontales y verticales. Estas redes se van articulando entre sí, conformando el tejido social. El predominio de unas sobre otras y su combinación dan el carácter a la cultura política (ej. autoritaria vs. igualitaria).

2) El sistema simbólico, por su parte, refuerza y legitima esa estructura de redes, e incluye manifestaciones tales como el discurso, los rituales políticos, el lenguaje, la arquitectura, los mitos de la cosmología política, los emblemas, el uso de tiempos y espacios, etc., elementos que a menudo son constitutivos de la ideología nacionalista.

\section{Redes sociales e intercambios}

Las redes sociales son construcciones abstractas que el investigador define de acuerdo al criterio que le interese; es decir, estas relaciones se determinan por algún criterio subyacente, lo que permite identificar estructuras sociales que generalmente no están formalmente definidas por la sociedad y que de otra manera no serían identificables. 
Lo que interesa al científico social es la forma en que las relaciones están ordenadas, cómo la conducta de los individuos depende de su ubicación en este ordenamiento y de qué manera influyen los propios individuos en los ordenamientos.

Así, se puede hacer un diagrama de las relaciones en las cuales se dan intercambios de bienes y servicios o de comunicación entre individuos, tales como intercambios de favores burocráticos, de préstamos materiales o de información. Los intercambios pueden ser de tres tipos: a) intercambios recíprocos (entre individuos con recursos y carencias similares que se dan dentro de un contexto de sociabilidad o "confianza"), b) de tipo redistibutivo (patrón/cliente); es decir, entre individuos de diferentes jerarquías con recursos desiguales, siendo éstas típicas relaciones de poder inmersas en relaciones personales y en las cuales se intercambia lealtad por protección, y c) intercambios de mercado, en los que la circulación de bienes y servicios se hace a través del mercado y sus leyes (Polanyi, 1957: 234-269). La reciprocidad y la redistribución representan formas de intercambio informales, social y culturalmente normadas, y se remontan a los orígenes de las sociedades humanas. Estas relaciones y sus formas de intercambio varían de cultura en cultura, tanto en la definición de quiénes son los 'partners' en el intercambio, como en lo que es susceptible de ser intercambiado y en las formas socialmente aceptadas de hacerlo; hay, pues, una estructura social en el interior de la cual se dan estos intercambios (las redes sociales verticales u horizontales), los objetos de intercambio (materiales y morales) y un sistema simbólico que refuerza la estructura de la red y de la sociedad en que ésta se desenvuelve.

En sociedades complejas el individuo debe manejar los tres tipos de intercambio (reciprocidad, redistribución y mercado); ello implica que participa simultáneamente de los tres tipos de relaciones sociales: una relación de confianza, una de jerarquía y otra de clase (ver Lomnitz, 1975, 1987, 1988 y 1991). Así, lo económico, lo político y lo sociocultural son tres dominios que se van enhebrando en la vida del individuo y su trama va conformando la realidad macrosocial (Radcliffe-Brown, 1952, y para la relación entre redes verticales y poder, ver Blau, 1964). Cada tipo de intercambio tiene sus reglas que el individuo aprende a manejar y -cuando son contradictorias- a conciliar entre sí para cada situación determinada. Ese proceso es rico en lenguaje simbólico, por lo tanto la habilidad para manejar símbolos a su vez constituye un recurso. 
Los recursos que se intercambian determinan y originan estructuras sociales características. Si tomamos los casos de México y Chile como ejemplos paradigmáticos, observamos en México sectores estructurados verticalmente, cruzados por redes horizontales. El capital y el poder se expresan mediante estructuras visibles que concentran a su alrededor a grupos de individuos que se ordenan jerárquicamente según el nivel de recursos a que tienen acceso. A través de esas jerarquías se van conformando patrones de lealtad, estilos de vida, ideologías y subculturas. A estas estructuras se van integrando redes horizontales de intercambio recíproco que aligeran la presión de las relaciones jerárquicas y les otorgan flexibilidad. Las estructuras o redes que se van conformando a niveles personales tienden a expresarse finalmente en el sistema político nacional; las redes horizontales, si son las dominantes, cristalizarán en partidos políticos de corte horizontal con liderazgos de cierto tipo, y las verticales, a su vez, generarán un tipo diferente de sociedad. Por ejemplo, México es un estado con un sistema corporativo, vertical, autoritario y muy presidencialista (una sociedad jerárquica afín a una sociedad de castas, en la cual la familia patriarcal, trigeneracional, ejerce el control sobre sus miembros); Chile es un país multipartidista, a cuyo interior se dan cohortes o grupos horizontales de amigos (que informalmente ejercen un cierto control entre sus miembros y que van creando las fronteras invisibles que los separan de los demás), con liderazgos condicionados, que producen -si bien un sistema presidencialista fuerte, también basado en una legitimidad casi fanática-, a la vez faccionalismos y un sistema con un parlamento fuerte; el sistema entero depende de negociaciones horizontales permanentes. Es una sociedad informalmente organizada en clases sociales estructuradas horizontalmente. A nuestro juicio, el modelo básico en la constitución de cada sociedad, sería el dado por las instituciones primarias - base de su sociabilidad y del control social- y serían ellas las que darían el carácter a su cultura política; en el caso de México, la familia patriarcal autoritaria y vertical, vs. el grupo de amigos en Chile. Si se trata de un estado-nación, sería su grupo socio-cultural dominante el que implantaría su sello sobre las instituciones nacionales.

Nuestros estudios preliminares realizados en la clase media (Lomnitz, 1971) sugieren que en la cultura política chilena existe un predominio de las relaciones horizontales sobre las verticales al interior de las clases sociales y que esto se refleja en sus organizaciones políticas. Es decir, que si bien existe una red generalizada de intercambios recíprocos entre miembros de la misma clase, se van concentrando redes más estrechas que eventualmente dan origen a su formalización en partidos políticos 
al interior de los cuales se dan intercambios de favores y comunicación, lealtades y recursos, dependientes del acceso que el partido tenga al poder estatal (Valenzuela, 1977). A su vez, al interior de los partidos y a medida que éstos crecen, se van dando cohortes o redes de amigos generacionales, cuya estructura interna es igualitaria, altamente emocional (generalmente comienzan estas redes a aparecer entre jóvenes adolescentes, en las Juventudes de los partidos). Al interior de estas redes igualitarias basadas en la amistad -que por definición se da entre iguales-, van surgiendo los líderes "naturales", una de cuyas características es su necesidad permanente y su capacidad de mantener su legitimidad al interior del grupo. Podríamos decir que si bien en México el líder crea el grupo, en Chile el grupo elige y crea al líder. Algunos de estos líderes van trascendiendo la red primaria, entrando a otros niveles jerárquicos dentro del partido, hasta llegar a los liderazgos más altos del mismo, siempre debiendo probarse como líderes y recibir la aceptación de las bases. Cuando esto no sucede, se producen fisuras, el surgimiento de facciones y eventualmente la separación de grupos que conforman nuevos partidos. Como resultado tenemos un faccionalismo típico de la cultura política chilena.

El notorio predominio de las relaciones horizontales basadas en la confianza, implicaría la posibilidad de que el acceso al poder se viera facilitado por estructuras más semejantes a redes horizontales que a jerarquías verticales. Sin embargo, ningún sistema social complejo puede prescindir de estas últimas. Los líderes resultan indispensables, y ello plantea para Chile una situación más difícil de resolver que en México, donde la horizontalidad es funcional, complementa y sostiene las jerarquías verticales. En Chile, en cambio, la jerarquía o liderazgo sería un elemento contradictorio con el ideal de horizontalidad y con el crecimiento de los partidos. Estas contradicciones se resuelven - a nivel del grupo- poniendo en juego mecanismos sui generis de la cultura política chilena, tales como la mofa burlesca (la "talla") al líder que intenta sobresalir o se muestra poco modesto, o directamente el tirarlo hacia abajo (el "chaqueteo"), el sacarlo de su función con malas artes (el "aserruchamiento de piso"), etc. Al mismo tiempo, se postula la necesidad de que los líderes sean y se muestren modestos, austeros, dedicados al bien común, apegados a la legalidad y sobre todo, que no abusen del poder. A otro nivel, si un líder llega a consolidar su poder personal al grado de construir su propia jerarquía vertical, el sistema tendería a erosionar su poder, ya sea provocando su derrota en las siguientes elecciones, o por la vía de la separación de grupos y la fundación de partidos disidentes, dando paso al faccionalismo. Cuando estos recursos no han sido efectivos, el sistema ha entrado en 
crisis, y en ocasiones, han aparecido soluciones autoritarias, que inevitablemente se basan en la coerción física. La naturaleza de la cultura política chilena hace necesario el respeto a la horizontalidad y a la verticalidad aceptada consensualmente y legal. En México en cambio, el predominio de la verticalidad tiende a concentrar el poder en los niveles mas altos de la sociedad o directamente en el presidente y a consolidar todas las fuerzas políticas en un solo gran partido, compuesto por sectores muy disímiles que negocian entre sí al interior del mismo; este autoritarismo tiene base en su cultura política; su estructura de redes y el sistema simbólico que la sostiene, por lo que puede ejercerse sin apoyarse en la fuerza física. A diferencia de México, en Chile el monopolio del poder en un solo partido o individuo, rompería la paz social basada en el sistema multipartidista de negociaciones y alianzas.

Así, si en México la horizontalidad complementa y sostiene las jerarquías verticales, en Chile, de acuerdo a nuestra hipótesis, la jerarquía (o liderazgo) sería un elemento conflictivo para el crecimiento de grupos horizontales (los partidos). El resultado de esta dinámica sería el faccionalismo, como mecanismo que limita el crecimiento de las estructuras jerárquicas e impide la consolidación de un liderato personalista, excepto el liderazgo legítimo y sujeto a crítica del presidente de la república. Las facciones resultantes generalmente están integradas por un número pequeño de personas, que representan un grupo de amigos pertenecientes a las capas dirigentes del partido (incluyendo los jóvenes; a menudo este faccionalismo expresa un conflicto generacional). Algunas veces, estas facciones crecen y se separan del tronco hasta convertirse en partidos de significación con un gran número de seguidores; tal es el caso del partido Radical (desgajado del P. Liberal) y del partido Demócrata Cristiano (salido del tronco conservador). Pero en la mayoría de los casos, estas facciones terminan uniéndose o aliándose con otros partidos, o se mantienen en el tiempo sin mayor significación o bien desaparecen. (Ver por ej., Moulian y Torres, 1990; Edwards y Frei, 1949; Vial, 1981).

Si bien el faccionalismo cumple un papel funcional al sistema de horizontalidades, impidiendo que los líderes acumulen poder excesivo o que algún partido logre una hegemonía política que le permita gobernar sin negociar, su exceso conduce a, o es expresión de, una crisis social y económica. En algunos ejemplos históricos de Chile, el autoritarismo ha surgido de tales situaciones (Presidentes Ibañez y Pinochet). Es decir, el exceso de faccionalismo pulveriza el sistema, cuyo equilibrio descansa en la existencia de dos o tres partidos básicos, que encarnen las grandes corrientes en que 
se divide la sociedad chilena, dependientes de la clase que representan y/o de su postura frente a la religión. Estos partidos, en tanto representantes de una de las grandes corrientes, son los que permanecen -con uno u otro nombre- haciendo que en Chile haya partidos de derecha, centro e izquierda, y a la vez, laicos y católicos (Scully, 1995: 136). ¿Como se da esta persistencia?

Afirmamos que, así como entre grupos étnicos o "minorías" pertenecientes a una misma nación, esta persistencia se da por una combinación de redes sociales compuestas por individuos que ocupan un mismo nicho económico y/o comparten una subcultura común, en el caso del sistema político, los partidos representan conjuntos de redes sociales de individuos que ocupan determinados nichos económicos y sociales, que van desarrollando formas de vida comunes que giran y se consolidan a través de compartir una misma ideología política. Al igual que las etnias o "minorías" constitutivas de una nación, los partidos van creando fronteras simbólicas que los distinguen de los otros, que los hacen sentirse diferentes de los otros: lo que Barth define como "we-ness" y que se expresan no solamente en las ideologías políticas, sino también en preferencias de estilos de vida, manera de entretenerse, colegios y universidades adonde se envían los hijos, ocupaciones, etc. En otras palabras, los partidos políticos representan subculturas características que llegan a garantizar su persistencia.

Es necesario subrayar que el hecho de destacar el predominio en Chile de la horizontalidad sobre la verticalidad no equivale a afirmar que no se de una sociedad jerarquizada puesto que los partidos políticos se organizan sobre bases clasistas, quedando sus diferencias de clase perfectamente marcadas en el tejido social del país. De lo que aquí se trata es de un modelo, susceptible de ser aplicado para explicar y comprender la cultura política de una sociedad. Su origen y la persistencia de su "gramática". En México, de la estructura primaria (la gran familia patriarcal) y de las pequeñas redes verticales de patrón/cliente articuladas verticalmente entre sí, se cristaliza un sistema político corporativo y presidencial. En Chile, a partir de las redes horizontales de grupos de amigos, se van conglomerando los partidos políticos, que dan por resultado una sociedad de clase, jerarquizada, aunque no autoritaria. En Chile lo que vemos a nivel macro, es una sociedad horizontalmente organizada, pero estratificada (aunque no impermeable), que parte de las subculturas de que hemos hablado. En suma, la base de estas subculturas es la clase social, pero la clase social definida por una mezcla de variables que incluyen no solo la posición del individuo en 
la economía, sino también las redes sociales que la componen, la cuestión religiosa y sus estilos de vida. Todo lo cual es muy notorio - por ejemplo, el modo de hablar-, y por lo tanto resulta muy característico de la sociedad chilena.

Por otra parte, en un sistema como éste, caracterizado por contener fuertes subculturas políticas, es muy importante garantizar la convivencia, lo cual requiere la aceptación de un marco reglamentario común: la legalidad. El respeto a esta legalidad, expresada en la constitución, es lo que legitima el sistema y la autoridad presidencial. Este aspecto de la cultura chilena ha estado presente desde sus inicios, y es uno de sus rasgos, quizás el más notorio.

Esto, en fin, es lo que llamamos una gramática social o cultura: las categorías sociales, las reglas con que se usan y la habilidad que cada cual tiene para comportarse dentro de ellas; la gramática y el habla, las estructuras primarias que resultan de ellas; y las organizaciones políticas en que se cristalizan y a través de las cuales se obtiene acceso y se ejerce el poder, son lo que da su carácter a la cultura nacional. Y por supuesto, en toda sociedad se dan relaciones verticales y horizontales; lo que daría su especificidad a cada una es la mezcla y combinación de ambas, y la importancia relativa de cada tipo de estructura.

Es en el contexto de estas ideas que hemos emprendido el estudio y análisis de los Partidos Radical y Demócrata Cristiano de Chile, en la gestación de los cuales, las redes de amistad, afinidad ideológica y social de carácter horizontal, son más que visibles. Vale decir, que ambos partidos comparten las características de la cultura política chilena en lo que se refiere a las estructuras de las redes sociales, horizontalidad y verticalidad, liderazgos condicionados, vida familiar, etc.. Pero que ostentan claras diferencias en lo que respecta a sus respectivos sistemas simbólicos (valores, discursos, ideología, estilos de vida, etc.).

Cabe acotar que el Partido Demócrata Cristiano (PDC) fue concebido como partido de clase media, ha mantenido lazos culturales con la clase alta (por haber surgido del Partido Conservador), logró -en la década de los 60s- convertirse en un partido pluriclasista, al atraer hacia su redil a grandes sectores del campesinado y del sector popular urbano. Esto apareció como problema al analizar los datos obtenidos en el trabajo de campo, ya que los estilos de vida de los militantes entrevistados de la DC varían de acuerdo a la clase social a la que pertenecen (el problema no se dio en el 
caso de los radicales). Pero la homogeneidad sí se manifiesta en lo que se refiere al tipo de catolicismo que profesan, a sus valores (humanistas cristianos), a su discurso y a cómo se perciben a sí mismos.

\section{Estudios de caso}

En el estudio se comenzó con una reseña histórica del siglo XIX y XX, la que permitió fundamentar el modelo teórico propuesto en lo que respecta a las características de la cultura política chilena. Allí vemos que el Partido Conservador, primer partido que surge después de la independencia, es el resultado de una inconformidad de la "fronda aristocrática" ante el comportamiento autoritario del Presidente de la República. Posteriormente, y con el surgimiento de otra red de la misma aristocracia - la red liberal- comienzan a aparecer diferencias ideológicas relativas a la injerencia de la Iglesia en los asuntos del Estado. De allí surge el Partido Liberal, del cual a su vez se desprende el Partido Radical a consecuencia de diferencias también referidas a la cuestión religiosa. Los radicales ya son categóricamente laicos, anticlericales, promotores de la educación laica, abanderados de los postulados librepensadores, positivistas, y humanistas de sus congéneres franceses y apoyados por la masonería. Todos estos principios, más los cambios socio-económicos vividos por el país durante el último tercio del siglo XIX, lo convierten en el abanderado de la incipiente clase media chilena. En este ejemplo histórico se ve cómo, de redes sociales homogéneas se desprenden nuevas redes horizontales que se van distinguiendo de las originales, y que abrazan una ideología diferente en gran medida debido a los cambios en el desarrollo económico del país y al papel que la nueva red pasa a desempeñar en él.

En el siglo XX la clase media experimenta un gran desarrollo, a causa de la necesidad de cuadros medios para servir en el ejército, para la explotación del salitre, para servir en la administración pública, en el sistema educacional, etc. Los profesionales liberales necesarios para apoyar este desarrollo, a su vez, son producto de la educación fiscal y sobre esta base se afianza el poderío del P. Radical. El sector popular urbano, ya afianzado en el siglo XX a raíz del desarrollo económico del país, también es una base de apoyo del emergente $P$. Radical, el cual juega un papel intermediador entre las clases desposeídas y la oligarquía nacional. En la primera mitad del siglo XX, con tres presidentes radicales sucesivos, el PR sienta las bases de la industrialización del país, da un auge al sistema de educación pública, se ocupa de la salud, etc., lo cual hace que crezca el aparato estatal, la burocracia, y junto con ello el propio Partido Radical. 
Mientras tanto, aparecen partidos marxistas de izquierda que empiezan a representar al proletariado urbano. Estos no solamente son partidos de clase, sino de ideología. A medida que aumenta la influencia del marxismo en Chile y en el mundo, la Iglesia Católica busca con mayor ahínco ofrecer una ideología alternativa en la defensa de los pobres, con su doctrina social de la Iglesia, expresada en sendas Encíclicas. Esta doctrina es asumida en Chile como base del pensamiento social de redes de estudiantes católicos los cuales eventualmente son absorbidos (como ANEC) por el P. Conservador y se siguen desarrollando en su interior hasta denominase Falange, pero terminan por abandonarlo, debido a las diferencias ideológicas que los separan tajantemente (iglesia conservadora vs. iglesia social) Al constituirse finalmente esta red como PDC, nuevamente una parte del P. Conservador -la red social-cristiana que ya venía operando en su interior- se separa del tronco y pasa a integrar el nuevo partido, el DC. Con esto, este nuevo partido contiene ya en su interior, dos redes de distinto origen social. Sin embargo, el grupo ideológicamente dominante es el de la Falange, el cual ofrece a la clase media católica una posibilidad de militancia política, acorde a sus postulados religiosos. Fuera de eso, con su ideología de justicia social, su interés es atraer no sólo a la clase media, sino también al campesinado y al proletariado urbano. El partido ha pasado a ser pluriclasista, pero unido por una fuerte ideología político-religiosa, que será la base del desarrollo de su subcultura.

El estudio de las subculturas de los dos partidos políticos involucrados en este trabajo, confirmó claramente la hipótesis original de la existencia de subculturas partidarias diferenciadas. Si bien ambos partidos, en general, son representantes de la clase media, y han tenido propuestas similares en lo que se refiere al papel del Estado en la sociedad, sus diferencias ideológicas básicas (laicismo vs. humanismo cristiano) atrajeron desde un principio grupos sociales diferentes. Por ejemplo, el PR se desarrolla originalmente en grupos de provincia, y sus costumbres, formas de vida, sociabilidad, responden a un cierto tipo de vida provincial. En cambio la Falange, -que da origen al PDC- comienza con grupos intelectuales universitarios santiaguinos, católicos, cuyos estilos de vida, menos gregarios y más austeros y moralistas, fueron imprimiéndole un carácter a la colectividad. Así vemos que el tipo de sociabilidad de provincia de los radicales y su ideología igualitaria y no sectaria, con mucho énfasis en la amistad, también se refleja en sus organizaciones formales e informales: la asamblea, abierta, como su órgano básico de sociabilidad política, y el Club Radical, como principal ámbito de sociabilidad. En contraste, el principal ámbito de sociabilidad 
de la DC es la familia, y en cuanto a la organización partidaria formal están las bases comunales, que no son abiertas, que están cerradas a todo el que no sea militante.

Mientras el radicalismo desde un principio puso el énfasis en la tolerancia, en la conciliación, en su "chilenidad", en la capacidad de negociación, en su amplitud de criterio, la DC, en su período formativo, propone la doctrina del camino propio, que básicamente- implica lo contrario; o sea, una tendencia excluyente de los demás. Resultan así recalcitrantes incluso a recibir nuevos militantes, sobre todo a nivel de base. A nivel de discurso, en los entrevistados esto se expresó en términos como "temor a los nuevos", "miedo a la infiltración", "necesidad de legitimarse dentro del partido", desconfianza de los llamados "advenedizos", etc.

Al analizar el discurso de cada partido, se advierte en lo formal, un acento distinto, una manera peculiar de hablar, y un vocabulario expresivo de los contenidos valóricos que les importan a cada uno. El discurso radical, pone el acento en los logros del partido en relación con el desarrollo de Chile, a sus grandes realizaciones en la historia del país: la laicización de algunas instituciones públicas (Registro Civil, cementerios), la implantación del concepto de Estado Docente, el establecimiento, por parte del Estado de una infraestructura que permitiera la modernización del país; por ejemplo, la creación de la Corporación de Fomento de la Producción. Fuera de esto, una parte central del discurso radical es el tema de la amistad: el ayudar a los amigos "de cualquier color", que los radicales son buenos amigos, e incluso el poner la amistad por encima de las cuestiones políticas. Por su parte, en el discurso de los democratacristianos - según se desprende de las entrevistas- no aparecen referencias a realizaciones partidarias en favor del país (aunque existan), pero en cambio, su discurso es esencialmente axiológico, basado en un "deber ser" que abarca a militantes de base, dirigentes, líderes nacionales, etc. es imperativo ser generoso, solidario, buen padre, buena madre, luchador por la justicia social, austero en su forma de vida, (en el comer y en el vestir). En relación con esto mismo, las críticas que hacen los radicales en relación con su partido, tienen que ver con acciones políticas de la dirigencia, como que se hayan aliado a la derecha, o el haber impulsado la Ley de Defensa de la Democracia, o cualquier error político cometido. Por otra parte, no tienen actitud crítica respecto al amiguismo o "compadrazgo", que la mayoría acepta, y descartan que sea un rasgo negativo. Al revés, lo justifican porque los amigos deben ayudarse entre sí, y los amigos no excluyen amigos de otro signo político. Por su parte, el discurso crítico de los DC respecto a su partido, está estrechamente vinculado a los imperativos del 
"deber ser" DC descrito más arriba, tanto para las bases como para los escalafones superiores. Equivocaciones políticas de los líderes DC, rara vez aparecieron en nuestras entrevistas.

Una última diferencia, notable, que marcaremos entre las dos subculturas, es la que se refiere al peso que ejerce la madre o el padre, sobre los hijos, en lo que se refiere a la adopción de la cultura política correspondiente. En el caso de los radicales, el padre sin excepción- fue la figura central y más influyente en el camino político adoptado por los hijos; y esto considerando que muchos, tenían madres católicas observantes. En el PDC, en cambio, entre nuestros entrevistados democratacristianos, es la madre católica, pero con inquietudes sociales, la portadora de la doctrina que puede llevar a la consecución de sus postulados. Hay que subrayar que la sociabilidad de los radicales se despliega más fuera de la casa, en grupos masculinos, mientras que la democratacristiana se centra en las casas, en la familia, donde la madre puede ejercer mayor influencia formadora y centralizadora, y es la que lleva a sus hijos a misa.

En resumen, a través de nuestro trabajo de campo pudimos distinguir claramente una "cultura radical" y una "cultura democratacristiana"; estas culturas o subculturas, pensamos, tienen más peso en el desarrollo y permanencia de cada partido, y perdura más - en el tiempo- que los principios de la ideología política. Ya que si bien hoy día, los distintos partidos que conforman la Concertación por la Democracia (alianza gobernante) han aceptado el modelo hoy imperante de conducción del país, con sus ingredientes de globalización, y neoliberalismo, así como desenfatización de la lucha de clases, persiste sin embargo una conciencia de colectividad con sus fronteras (boundaries) simbólicas; es decir, lo que los distingue de sus aliados de hoy es su subcultura; del hecho de que se reconocen como diferentes y ven como diferentes a los demás.

\section{Bibliografía}

Blau, Peter (1964). Exchange and Social Power in Social Life. NewYork: J ohn Wiley and sons.

Edwards, Alberto y Eduardo Frei (1949). Historia de los Partidos Políticos Chilenos. Santiago de Chile: Editorial del Pacífico.

Lomnitz, Larissa (1971). "Reciprocity of Favours in the Chilean Middle Class" en Studies in Economic Anthropology, compilado por Gweorge Dalton, Washington, AAA.

Lomnitz Adler, Larissa (1975). Cómo sobreviven los marginados. México: Siglo XXI 
Lomnitz Adler, Larissa y Marisol Pérez Lizaur (1987). A Mexican Elite Family. Princeton: Princeton University Press.

Lomnitz Adler, Larissa y Leticia Meyer (1988). La Nueva Clase. México: UNAM.

Lomnitz Adler, Larissa y Ana Melnick (1991). Chile's Middle Class. Boulder, Colorado: Lynne Rienner Pub.

Lomnitz Adler, Larissa y Ana Melnick (1998). La cultura política chilena y los partidos de centro. Una explicación antropológica. Santiago de Chile: Fondo de Cultura Económica.

Moulian, Tomás e Isabel Torres Dujicin (1990). Discusión entre Hombres. Santiago de Chile: FLACSO.

Polanyi, Karl (1957). Trade Market and Early Empires. New York: Fress Press.

Radcliff-Brown, A.R. (1952). Structure and Function in Primitive Society. Londres: Cohen and West.

Scully, Timothy (1995). "Reconstituting Party Politics in Chile", en Scott Mainwaring y Timothy R. Scully (eds.) Building Democratic Institutions. Party Systems in Latin America. Standford: Standford University Press.

Valenzuela, Arturo (1977). Political Brokers in Chile: Local government in a Centralized Polity. Durkham, N.C.: Duke University Press.

Valenzuela, Arturo (1989). El Quiebre de la Democracia en Chile. Santiago de Chile: FLACSO

Vial Correa, Gonzalo (1981). Historia de Chile (1891-1973). Santiago de Chile: Editorial Santillana, vols. I, II, III. 